S. Mesić, E. Martinac*

\title{
PROCJENA RIZIKA RADNOG MJESTA U ZAGREBAČKOM HOLDINGU d.o.o.
}

UDK 352.9:613.6

PRIMLJENO: 17.1 .2017$.

PRIHVAĆENO: 11.4 .2017$.

\begin{abstract}
SAŽETAK: Procjena rizika radnog mjesta obavlja se identifikacijom opasnosti i štetnosti na radnom mjestu s ciljem prepoznavanja njihovog mogućeg utjecaja na radno mjesto. Procjena rizika radnog mjesta definira mjere za prevenciju profesionalnih bolesti i ozljeda na radu, ali i djeluje na zaštitu zdravlja i smanjivanje troškova.

Cilj ovog istraživačkog rada bio je prepoznavanje odnosa između uvjeta rada na radnim mjestima komunalni redar, smetlar i vrtlar u Zagrebačkom holdingu d.o.o. i mogućih ishoda za zdravlje zaposlenih u svrhu procjene rizika i poboljšanja njihova zdravlja.

$U$ istraživanje se uključilo 137 ispitanika (116 muškaraca i 21 žena), prosječnog radnog staža 16 godina, koji na sadašnjim poslovima rade u prosjeku 12 godina. Ispitivanje je provedeno anonimnim upitnikom načinjenim za ovo istraživanje.

Najčešće nepovoljne značajke rada koje opisuju ispitanici su obavljanje pretežno fizičkog posla, rada na otvorenom, rada u prisilnom položaju koji uključuje klečanje, čučanje, pognut položaj, rad s otpadom i rad sa strankama. U 122 ili 89,0 \% ispitanika utvrđene su kronične bolesti koje su najčešće u vezi s bolestima mišićno-koštanog sustava (45 ili 32,8\%).

Kroničnu bolest 40 ili 35,7\% ispitanika povezuje sa sadašnjim radnim mjestom. Istraživanje je potvrdilo najčešću zastupljenost bolesti mišićno-koštanog sustava čija se pojavnost podudara $s$ vremenom zapošljavanja na radnim mjestima komunalni redar, smetlar i vrtlar. To ukazuje na potrebu osmišljavanja preventivnih, tehničkih i organizacijskih mjera za smanjenje rizika na radu, poglavito za bolesti mišićno-koštanog sustava uz poticanje pozitivnog, odgovornog, ponašanja radnika u brizi za vlastito zdravlje.
\end{abstract}

Ključne riječi: radna mjesta komunalni redar, smetlar i vrtlar, procjena rizika i poboljšanja zdravlja, prevencija

\section{UVOD}

Prilikom definiranja zahtjeva radnog mjesta potrebno je težiti formiranju radnih mjesta koja pružaju mogućnost da radnik zadrži i očuva zdravlje i radnu sposobnost bez obzira na rad-

*Srebrenka Mesić, dr. med., univ. mag. medicine rada i sporta (srebrenka.mesic@hzzo.hr), Hrvatski zavod za zdravstveno osiguranje, RU Zagreb, Ivekovićeva 17,10000 Zagreb, Eos Martinac, dr. med., Zavod za vještačenje, profesionalnu rehabilitaciju i zapošljavanje osoba s invaliditetom, Mihanovićeva 3, 10000 Zagreb. ni proces kojega je dio. Zdravo radno mjesto i zdrav radnik plod su uspješne suradnje izabranog doktora medicine primarne zdravstvene zaštite, poslodavca, stručnjaka zaštite na radu i specijaliste medicine rada.

Pravovremeno prepoznavanje rizičnih čimbenika je od primarne važnosti jer uključuje aktualno stanje na radnom mjestu, pri čemu je važno osobno viđenje radnika. Prepoznavanje odnosa između uvjeta rada na radnim mjestima komunalni redar, smetlar i vrtlar u Zagrebačkom 
holdingu d.o.o. i mogućih ishoda za zdravlje zaposlenih u svrhu procjene rizika i poboljšanja njihova zdravlja je glavni cilj ovog istraživanja. Istraživanje je obuhvatilo zaposlene na radnim mjestima koja imaju zajedničke karakteristike: obavljanje pretežno fizičkog posla, rad na otvorenom, rad u prisilnom položaju koji uključuje klečanje, čučanje, pognut položaj, rad s otpadom i rad sa strankama.

U navedenim zanimanjima moguća je veća zastupljenost bolesti povezanih s radom upravo zbog svoje zahtjevnosti i specifičnosti.

Cilj ovog istraživačkog rada bio je prepoznavanje odnosa između uvjeta rada na radnim mjestima komunalni redar, smetlar i vrtlar u Zagrebačkom holdingu d.o.o. i mogućih ishoda za zdravlje zaposlenih u svrhu procjene rizika i poboljšanja njihova zdravlja.

Specifični ciljevi ovoga istraživanja su utvrđivanje: (1) zdravstvenih poteškoća u radnika zaposlenih na navedenim radnim mjestima; (2) čimbenika rizika za njihovo zdravlje u kontekstu tjelesnog, duševnog i socijalnog zdravlja; (3) specifičnih značajki pojedinih ispitivanih skupina.

\section{ISPITANICI I METODE}

U istraživanje se dobrovoljno uključilo 137 ispitanika (116 muškaraca i 21 žena), prosječnog radnog staža 16 godina, koji na sadašnjim poslovima rade u prosjeku 12 godina. Ispitivanje je provedeno anonimnim upitnikom načinjenim za ovo istraživanje. Ispitanici su opisivali uvjete radnog mjesta, dostupnost i korištenje zaštitnih sredstava, subjektivno zadovoljstvo uvjetima radnog mjesta, učestalost kroničnih zaraznih bolesti, vremensko pojavljivanje zdravstvenih poteškoća u odnosu prema sadašnjem radnom mjestu, zastupljenost bolesti prema organskim sustavima, osobne navike kao što su pušenje, pijenje alkohola, pojavu ozljeda na radu i profesionalnih bolesti te razloge izostanaka s posla povezane s privremenom nesposobnosti za rad.

Rezultati rada prikazani su grafički uz primjenu metode deskriptivne statistike.

\section{REZULTATI RADA}

Najčešće nepovoljne značajke rada koje opisuju ispitanici su obavljanje pretežno fizičkog posla, rada na otvorenom, rada u prisilnom položaju koji uključuje klečanje, čučanje, pognut položaj, rad s otpadom i rad sa strankama. Većina ispitanika 102 (74\%) uz opis „pretežno fizički posao", pri čemu se pridjev pretežno odnosi na razdoblje od 2/3 radnog vremena, navodi pretežno fizički posao. Od toga broja 42 ispitanika (41\%) radi u prisilnom položaju koji uključuje klečanje, čučanje i pognut stav, te rad u prisilnom položaju. Gotovo svaki drugi ispitanik, njih 60 (43\%) navodi da rad obavlja u smjenama, 57 ispitanika (41\%) radi sa strankama, a 56 (54\%) obavlja posao s otpadom/ smećem.

Subjektivno osjećaj zadovoljstva uz mogućnost manjih ispravaka opisuje 71 (52\%) ispitanika, dok njih 66 (48\%) smatra da uvjeti radnog mjesta ne zadovoljavaju. Na pitanje o dostupnosti zaštitnih sredstava 71 (52 \%) ispitanika navodi da su zaštitna sredstva dostupna, i da ih u većini 115 (83\%) ispitanika koristi u redovnom radu.

U 122 ili 89,0 \% ispitanika utvrđena je kronična bolest koja je najčešće povezana s bolestima mišićno-koštanog sustava (45 ili 32,8 \%). Kroničnu bolest 40 ili 35,7 \% ispitanika povezuje sa sadašnjim radnim mjestom.

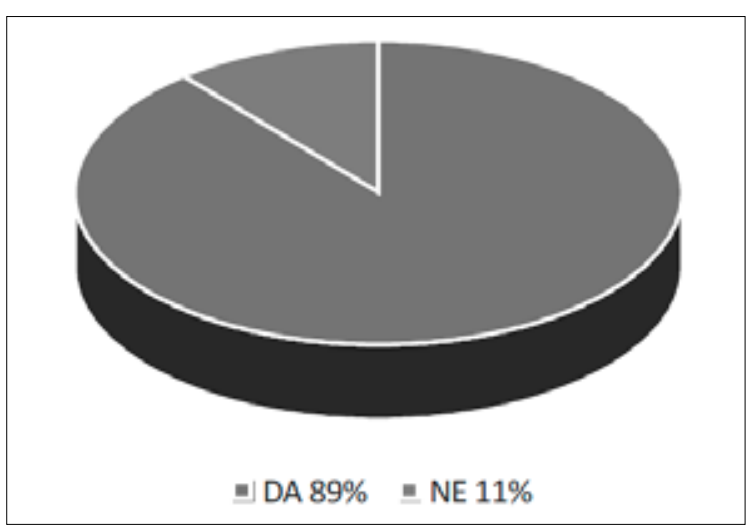

Grafikon 1. Pojavnost kroničnih bolesti Graph 1. Incidence of chronic diseases 


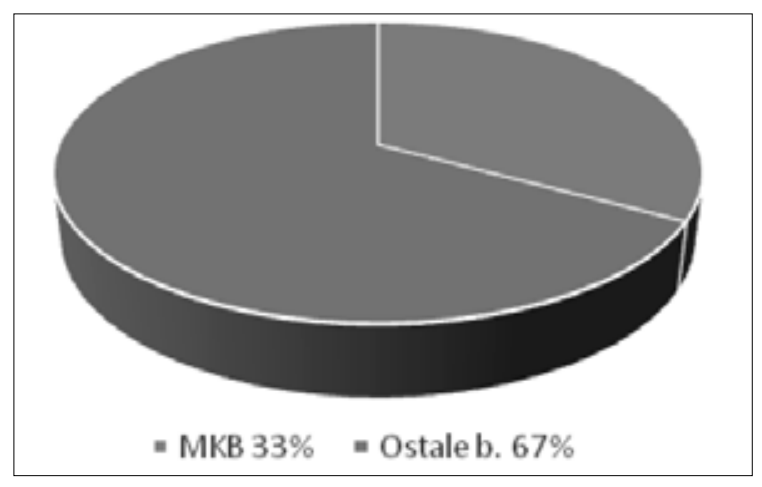

Legenda: MKB - mišićno-koštane bolesti

Grafikon 2. Pojavnost MKB-a

Graph 2. Incidence of musculoskeletal diseases

Pušenje je zastupljeno u gotovo svakog drugog ispitanika (59 ili $43 \%$ ), a povišena tjelesna težina u svakog četvrtog ispitanika (33 ili 24,0 \%).

Kada se podatci uspoređuju između tri skupine ispitanika koji rade na različitim radnim mjestima, nalazi se da radna mjesta smetlar i vrtlar imaju veću incidenciju pojavnosti bolesti mišićno-koštanog sustava, ali i veću incidenciju ozljeda na radu kod 19 (20\%) ispitanika.

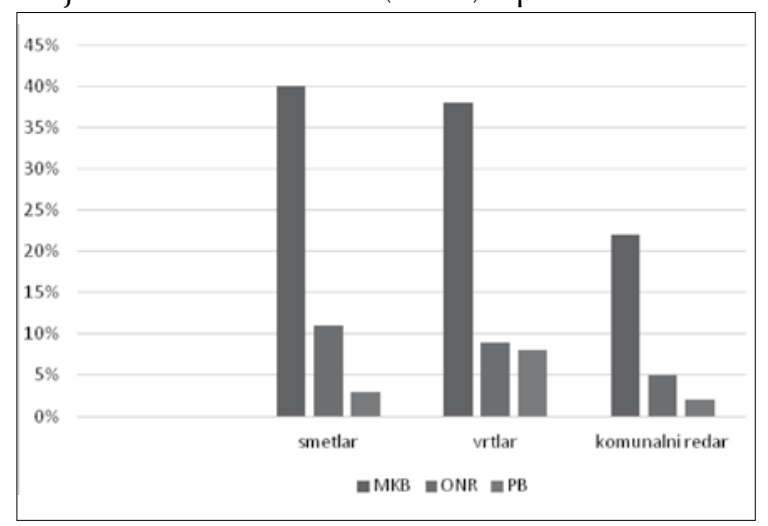

Legenda: MKB - mišićno-koštane bolesti; ONR - ozljede na radu; $\mathrm{PB}$ - profesionalna bolest

Grafikon 3. Usporedni prikaz pojavnosti MKB-a, ONR-a i $P B$-a

Graph 3. Parallel overview of musculoskeletal disease, workplace injury and occupational disease incidence

Priznata profesionalna bolest povezana s bolesti mišićno-koštanog sustava najviše je zastupljena u skupini vrtlara.
U skupini komunalnih redara koji u opisu posla u većini ispitanika 39 (78\%) obavljaju posao koji uključuje rad sa strankama zamijećena je $\mathrm{u}$ istom omjeru zastupljenost psihičkih bolesti i poremećaja kao i bolesti mišićno-koštanog sustava.

U zadnje dvije godine je 84 ili $61 \%$ ispitanika izostalo s posla, od čega je do 30 dana s posla izostalo 49 ili 58,3 \% ispitanika, a više od 30 dana 35 ili 41,6\%. Kao razlog izostanaka s posla je u 43 ili 51,2 \% slučajeva bila akutna bolest, kronična bolest je kao uzrok izostanka s posla zabilježena kod 21 ili 25,0 \% ispitanika, a ostale okolnosti koje umanjuju radnu sposobnost navelo je 20 ili 23,8 \% ispitanika. Priznatu ozljedu na radu imala su 24 ispitanika (18\%), te 6 priznatih profesionalnih bolesti (4\%), i to u 4 vrtlara.

\section{RASPRAVA}

Prema podatcima Međunarodne organizacije rada (engl. International Labour OrganizationILO), u svijetu svakoga dana 6.300 radnika izgubi život zbog posljedica ozljede na radu, profesionalne bolesti ili bolesti povezane s radom, time godišnje život izgubi 2,3 milijuna radnika. Statistike pokazuju da se svakih 15 sekundi 160 radnika ozlijedi obavljajući svoj posao, što na godišnjoj razini znači 317 milijuna ozljeda na radu (www.ilo.org). Mnoge od spomenutih ozljeda na radu, profesionalnih bolesti i bolesti povezanih s radom za posljedicu imaju dugotrajno liječenje i oporavak, višemjesečnu privremenu radnu nesposobnost i invalidnost. Rano prepoznavanje štetnih radnih uvjeta može djelovati na procjenu rizika, poboljšanje i očuvanje zdravlja.

Ozljede na radu, profesionalne bolesti i bolesti povezane s radom posljedica su izloženosti radnika opasnostima, štetnostima i naporima radnog mjesta. Opasnosti radnog mjesta najčešći su uzrok nastanka ozljeda na radu, dok štetnosti i napori uglavnom uzrokuju nastanak profesionalnih bolesti i bolesti povezanih s radom (www.who). Svjetska zdravstvena organizacija definirala je bolest povezanu s radom kao poremećaj koji proizlazi iz niza čimbenika, pri čemu radna okolina i obavljanje posla znatno pridonose jačini i pojavi bolesti (www.who). 
Bolesti povezane s radom ili prema EUROSTAT-u "zdravstveni problemi povezani s radom" su bolesti u kojim štetnost na radnom mjestu predstavlja jedan od više mogućih uzročnih čimbenika za nastanak ili pogoršanje već postojeće bolesti (Zavalić, 2016.). Zbog sve veće učestalosti bolesti povezanih $\mathrm{s}$ radom $\mathrm{u}$ radno aktivnoj populaciji, osobito zbog troškova koje pojedine države imaju u vezi s liječenjem, rehabilitacijom, privremenom nesposobnosti za rad i prijevremenim umirovljenjem, ova skupina bolesti zaokuplja pozornost radnika, poslodavaca, liječnika, te fondova zdravstvenog i mirovinskog osiguranja. Na zdravstvene probleme uzrokovane radom godišnje se u svijetu tuži oko 160.000.000 ljudi ili 64 radnika na svakih 1.000 zaposlenih (www.who).

Najčešći opasni i štetni radni uvjeti u današnjim radnim procesima su mehaničke opasnosti, statodinamički napori i stresna radna mjesta $(Z a-$ valić, 2016.). Za razliku od europskih pokazatelja, u Republici Hrvatskoj su bolesti dišnog sustava (industrijski bronhitis i kronična opstruktivna plućna bolest kao najučestalije bolesti) i bolesti sustava za kretanje (sindrom bolnih leđa i bolni vrat kao najučestalije bolesti) svrstane među bolesti povezane $\mathrm{s}$ radom, a ne $\mathrm{u}$ profesionalne bolesti s obzirom na višeznačnu etiologiju ( $Z a-$ valić, 2016.).

Mišićno-koštane bolesti su najčešći uzrok kronične nemaligne boli, ali i privremene nesposobnosti za rad u Republici Hrvatskoj, a istovremeno su najvažniji razlog gubitka godina "zdravog" života izgubljenih zbog nesposobnosti (engl. disability-adjusted life year - DALYS) uvidom u Hrvatski zdravstveno-statistički ljetopis za 2012. godinu (Hrvatski zavod za javno zdravstvo, 2012.).

Pojam mišićno-koštane bolesti povezane s radom (engl. Work-related Muskulosceletal Disorder-WRMSDs) označava zdravstvene probleme sustava za kretanje, mišića, tetiva, kostiju, hrskavica, krvožilnog sustava, ligamenata i živaca odnosno svih mišićno-koštanih poremećaja koji su inducirani ili pogoršani tijekom obavljanja rada i okolnosti same izvedbe rada (www.fitforworkeurope.eu).
Pretpostavka je da je oko $30 \%$ radnika u razvijenim europskim zemljama, te oko 50 do $70 \%$ radnika u nerazvijenim zemljama u tranziciji izloženo teškom fizičkom radu ili radu u ergonomski neprimjerenim uvjetima, što ujedno predstavlja vodeći uzrok ozljeda na radu i bolesti povezanih s mišićno-koštanim sustavom. Procjene iz Velike Britanije opisane $u$ analizi Ankete o radnoj snazi (2015.) pokazuju da je ukupan broj WRMSDs slučajeva (prevalencija) u 2014./15. bio 553.000 od ukupno 1.243.000 za sve poslove povezane s radom (44\% od ukupnog broja). Kako bolesti mišićno-koštanog sustava povezanih s radom (WRMSDs) označavaju bolesti i poremećaje mišića, tetiva i živaca, a radni proces se uobičajeno izvodi uz upotrebu ruku i /ili nogu, pojava takvih bolesti može izazvati promjene ili pogoršanje na mišićno-koštanom sustavu. Uobičajeni pokreti rukama i nogama ne izazivaju štetne posljedice u redovnim, svakodnevnim aktivnostima, ali i u slučajevima kada je organizam doveden u situaciju da iste pokrete obavlja uzastopno, često i uz upotrebu sile, te kada između navedenih aktivnosti nema dovoljno vremena za oporavak, takve aktivnosti mogu biti štetne i mogu pogoršati ili uzrokovati bolest povezanu s radom (Statistics, Great Britain, 2015.). WRMSDs uključuju rad uz prisilne položaje tijela, stalno ponavljanje određenih pokreta, djelovanje jače sile na dijelove tijela kao što su ruke i zglobovi, ali i radni ritam koji ne dopušta vremenski dovoljan oporavak između aktivnosti. Vrlo često je prisutna interakcija više navedenih čimbenika uz štetan utjecaj čimbenika okoline kao što su toplina, hladnoća, vibracije i slično (Statistics, Great Britain, 2015.).

Većina WRMSDs razvija se postupno, može izazivati blage ili teške poremećaje, a pojavnost može biti epizodna ili dugotrajna - kronična, uz mogućnost izazivanja ili veće incidencije ozljeda na radu. Ipak ovi poremećaji su u rijetkim slučajevima opasni za život, ali nesporno imaju osim utjecaja na radnu učinkovitost i veliki utjecaj na kvalitetu života.

Sindrom bolnih leđa (engl. low-back pain), sindrom bolnog vrata (engl. neck-pain) i tortikolis u Republici Hrvatskoj imaju najveću pojav- 
nost kao bolesti povezane s radom (Babić-Naglić, 2012.). Degenerativne bolesti perifernih zglobova, kralježnice, koje su normalna posljedica trošenja i degeneracije zglobne hrskavice, mogu biti pogoršane obavljanjem rada, a fizička opterećenja, rad u nepovoljnom i prisilnom položaju tijela i broj pokreta djeluju na težinu kliničke slike bolesti ili njezino pogoršanje.

Uvidom u pokazatelje vodećih uzroka privremene nesposobnosti za rad za 2015. godinu koji se odnose na bolesti i ozljede prema podatcima Hrvatskog zavoda za zdravstveno osiguranje, bolesti mišićno-koštanog sustava su vodeći uzrok privremene nesposobnosti za rad. Od toga u Republici Hrvatskoj je najčešća pojavnost dorzopatija (58\%), reumatoidnog artritsa i spondiloartritisa (5\%), artroze (10\%) i ostale bolesti (27\%). Vodeći uzrok oštećenja mišićno-koštanog sustava u populaciji 0-19 su artropatije (M00-M25) i dorzopatije (M40M54). U radno aktivnoj dobi vodeći uzrok su dorzopatije (M40-M54) dok su u populaciji 65+ vodeći uzrok artropatije (M00-M25) prema Hrvatskom zdravstveno-statističkom ljetopisu za 2012. godinu.

Od sindroma bolnih leđa povremeno boluje od 20 do $40 \%$, a trajno približno $18 \%$ svih radnika mlađih od 45 godina. Povremeno boluje $60 \%$, a trajno oko $40 \%$ svih radnika starijih od 45 godina. Pri tome i štetnosti radnog mjesta kao što su teški fizički rad uz ponavljajuće zakretanje trupa, saginjanje, povlačenje, guranje, dizanje ili prenošenje tereta utječu na pojavnost i zastupljenost bolesti mišićno-koštanog sustava (Bogadi-Šare, Zavalić, 2009.).

\section{ZAKLJUČAK}

Radni procesi promatranih zanimanja komunalni redar, smetlar i vrtlar koji uključuju pretežno fizički posao, rad na otvorenom, rad u prisilnom položaju uz klečanje, čučanje, pognut položaj i rad s otpadom te štetan utjecaj čimbenika okoline kao što su toplina, hladnoća i slično, izazivaju promjene ili pogoršanje zdravstvenih poteškoća. Radna mjesta vrtlara i smetlara koja opisuju statodinamički napori i mehaničke opasnosti utječu na veću zastupljenost bolesti mišićno-koštanog sustava čija se pojavnost podudara s vremenom zapošljavanja, ali i na veću incidenciju ozljeda na radu. U navedenim zanimanjima zamjetna je veća zastupljenost bolesti koje se mogu povezati s obavljanjem zahtjevnih i specifičnih radnih procesa.

Najčešće zdravstvene poteškoće u radnika zaposlenih na navedenim radnim mjestima su mišićno-koštane bolesti.

Osim spomenutih opasnosti radnog mjesta, u sve tri skupine znatno su utjecale osobne navike u vezi s prekomjernom težinom i pušenjem. Odgovornost prema vlastitom zdravlju i mijenjanje navika može bez većih ulaganja spriječiti ili odgoditi pojavu simptoma.

Sve navedeno ukazuje na potrebu osmišljavanja preventivnih postupaka u svrhu očuvanja zdravlja u odnosu na njihov rad i radne zadaće, uz obvezne tehničke i organizacijske mjere za smanjenje rizika na radu, poglavito za bolesti mišićno-koštanog sustava.

Pravilna procjena rizika pri radu mora uvijek uključivati sam posao, radni okoliš te ukupna tjelesna i psihološka obilježja radnika. Prepoznavanje svih navedenih obilježja, uključujući profesionalne i neprofesionalne čimbenike rizika, može utjecati na očuvanje zdravlja radnika, a time i na veću produktivnost rada. Nužna je suradnja i koordinacija obiteljskih liječnika, liječnika medicine rada i poslodavca zbog sprečavanja preranog nastanka ovih bolesti, posljedičnih izostanaka s posla i prerane invalidnosti.

\section{LITERATURA}

Adele, R., Pinder, A. and Monnington, S.: Musculoskeletal problems in bricklayers, carpenters and plasterers: Literature review. Health and Safety Laboratory UK, 2013. U: Corbett, J.: Epidemiology of Work Related Disease, British Medical Journal, 1995.

Anderson, GBJ.: Epidemiologic aspects on low back pain in industry, Spine, 1981., 6, 53-60. 
Arnau, J.M., Pellise, F. and Vallano, N.P.: European guidelines for the management of low back pain. European Spine Journal, 15, 2006. suppl 2, 125-127.

Babić-Naglić, Đ.: Kronična mišićnokoštana bol - epidemiologija i faktori rizika. Fiz rehabil med, 2012., suppl 1, 1-250.

Bogadi-Šare, A., Zavalić, M.: Bolesti sustava za kretanje, Sigurnost, 51, 2009., 4, 321 - 331.

Centers for Disease Control and Prevention (CDC) Public health and aging: projected prevalence of self-reported arthritis or chronic joint symptoms among persons aged $>65$ years United States, 2005-2030. MMWR Morb Mortal Wkly Rep, 52, 2003., 21, 489-91.

Convention No. 121 and Recommendation No. 121

Encyclopedia of Occupational Health and Safety, 4th edition, Ed. Stellman JM, International Labour Office, Geneve, 1998.

Fadi A. Fathallah: Musculoskeletal disorders in labour - intensive agriculture applied ergonomics, 2010., Dostupno na: http://www.ncbi. nlm.nih.gov/pubmed/20398891. Pristupljeno: 12.12.2016.

Fejer, R. and Ruhe, A.: What is the prevalence of musculoskeletal problems in the elderly population in developed countries? A systematic critical literature review. Chiropr Man Therap, 20, 2012., 1- 31. doi:10.1186/2045-709X-20-31.

Fit for work europe. Musculoskeletal Disorders in the European Workforce. 30.12.2009. Dostupno na http://www.fitforworkeurope. eu/Default.aspx.LocID-0afnew00e.RefLocIDOaf002.Lang-EN.htm. Pristupljeno 20.12.2016.

Hignett, S. and Fray, M.: Manual handling in health care. Proceedings of the 1st Conference of the Federation of the European Ergonomics Societies [FEES], Bruges, Belgium, 10-12 October 2010.

Hrvatski zdravstveno-statistički ljetopis za 2012. godinu. Hrvatski zavod za javno zdravstvo, Zagreb, 2012. http://europe.osha.eu.int/good-practice/risks/ mds/disorder-links.asp?id=1

Hutson, M. and Ellis, R.: Textbook of Musculoskeletal Medicine. Oxford University Press, 2006.

Macdonald, W. and Oakman, J.: Requirements for more effective work place risk management of musculoskeletal disorders. Centre for Ergonomics \& Human Factors, La Trobe University, Melbourne, Victoria, Australia, 2015.

Mesić, S., Turčić, N., Mustajbegović, J.: Ocjena radne sposobnosti u zdravstvenom i mirovinskom osiguranju, Medicinska naklada, Zagreb, 2016.

Mrduljaš-Đujić, N.: Reumatološki bolesnik. U: Rumboldt, M., Petric, D.: Obiteljska medicina. Odabrana poglavlja. Medicinski fakultet Sveučilišta u Splitu, Split, 2011., str. 271-7.

Nacionalna strategija razvoja zdravstva 2012. - 2020., 2012.

National Institute Occupational Safety and Health (2015), Dostupno na: http://www.cdc. gov/niosh/topics/construction/. Pristupljeno: 2.1.2017.

Okunribido, O. and Wynn, T.: Ageing and work related musculoskeletal disorders. The Health and Safety Laboratory UK. Research Report 799, 2010.

Pravilnik o poslovima s posebnim uvjetima rada, N.N., br. 5/84.

Rayson, M. P.: Fitness for work: theneed for conducting a job analysis, Optimal Performanceltd, Farnham, Surrey, UK, Occup. Med., 50, 2006., 434-436.

Rom, WR. (ed.): Environmental and Occupational medicine, 3rd ed., Lippincott-Raven Publication, Philadelphia, New York, 1998.

Savinainen, M., Nygard, C. and Ilmarinen, J.: Workload and physical capacity among ageing municipal employees-A 16-year follow-up study, International Journal of Industrial Ergonomics, 34, 2004., 519-533. 
THOR The Health and Occupation Research Network (2015) University of Manchester, Dostupno na: (http://www.population-health. manchester.ac.uk/epidemiology/COEH/research/thor/). Pristupljeno: 13.12.2016.

Wijnhoven, $\mathrm{HAH}$, Vet, HCW de, Picavet, HSJ.: Prevalence of musculoskeletal disorders is systematically higher in women than in men. Clin J Pain, 22, 2006., 717-24.

Wilkie, R., Tajar, A., McBeth, J.: The onset of widespread musculoskeletal pain is associated with a decrease in healthy ageing in older people: a population-based prospective study. PLoS One, 8, 2013., 3, e59858. doi: 10.1371/journal. pone.0059858.
Work-related Musculoskeletal Disorder (WRMSDs), Statistics, Great Britain, 2015.

www.ilo.org/global/statistics-and-databases/ lang--en

Zakon o obveznom zdravstvenom osiguranju, N.N., br. 80/13., 137/13.

Zavalić,M.: Bolesti vezane uz rad, Dostupno na: https://www.zdravstvo.com/medrada/radovi/ zavalic.htm, Pristupljeno: 19.12.2016.

Zavalić, M.: Bolesti vezane uz rad, Dostupno na: www.mirovinsko. hr/UserDocslmages/ publikacije/.../ cl4\%20046-057, Pristupljeno: 19.12.2016. 


\section{EVALUATION OF WORKPLACE RISK AT} ZAGREB HOLDING LTD.

SUMMARY: Evaluation of workplace risk is performed by identifying risks and hazards in the workplace and recognising their potential impact on the workplace. Workplace risk evaluation proposes measures for prevention of occupational diseases and accidents at work, but it also improves health protection and cost reduction.

The main objective of the research is to recognise the relationship between the working conditions of a municipal policeman, garbage man and gardener at Zagreb Holding Ltd. and the possible health outcomes related to these three workplaces, with the aim of assessing risk and improving health.

A total of 137 subjects (116 men and 21 women), with an average working experience of 16 years, of which 12 at their current jobs, were included in the research. The survey was conducted using anonymous questionnaires which were custom-made for this study.

The most common adverse work characteristics described by the subjects were: performing predominantly physical work, working outside, working in unnatural body positions such as kneeling, squatting or stooping, working with garbage and working with people. A total of 122 examinees $(89.0 \%)$ developed chronic diseases, often associated with diseases of the musculoskeletal system (45, or 32.8\%). Forty participants (35.7\%) associated their chronic disease with their present working position.

The study confirmed that the most common diseases are those that affect the musculoskeletal system and that their incidence coincides with the beginning of employment as municipal policeman, garbage man and gardener.

Key words: municipal policeman, garbage man, gardener, risk assessment, health improvement, prevention

Original scientific paper

Received: 2017-01-17

Accepted: 2017-04-11 